\title{
Article
}

\section{The Association of Dyslexia and Developmental Speech and Language Disorder Candidate Genes with Reading and Language Abilities in Adults}

\author{
Catherine Doust ${ }^{1}$, Scott D. Gordon ${ }^{2}$, Natalie Garden ${ }^{2}$, Simon E. Fisher ${ }^{3,4}$, Nicholas G. Martin ${ }^{2}$, Timothy C. Bates ${ }^{1}$ and \\ Michelle Luciano ${ }^{1}$ \\ ${ }^{1}$ Department of Psychology, The University of Edinburgh, Edinburgh, Scotland, UK, ${ }^{2}$ Genetic Epidemiology Laboratory, QIMR Berghofer Medical Research \\ Institute, Brisbane, Queensland, Australia, ${ }^{3}$ Language and Genetics Department, Max Planck Institute for Psycholinguistics, Nijmegen, the Netherlands and \\ ${ }^{4}$ Donders Institute for Brain, Cognition and Behaviour, Nijmegen, the Netherlands
}

\begin{abstract}
Reading and language abilities are critical for educational achievement and success in adulthood. Variation in these traits is highly heritable, but the underlying genetic architecture is largely undiscovered. Genetic studies of reading and language skills traditionally focus on children with developmental disorders; however, much larger unselected adult samples are available, increasing power to identify associations with specific genetic variants of small effect size. We introduce an Australian adult population cohort (41.7-73.2 years of age, $N=1505)$ in which we obtained data using validated measures of several aspects of reading and language abilities. We performed genetic association analysis for a reading and spelling composite score, nonword reading (assessing phonological processing: a core component in learning to read), phonetic spelling, self-reported reading impairment and nonword repetition (a marker of language ability). Given the limited power in a sample of this size ( $\sim 80 \%$ power to find a minimum effect size of 0.005$)$, we focused on analyzing candidate genes that have been associated with dyslexia and developmental speech and language disorders in prior studies. In gene-based tests, FOXP2, a gene implicated in speech/language disorders, was associated with nonword repetition $(p<.001)$, phonetic spelling $(p=.002)$ and the reading and spelling composite score $(p<.001)$. Geneset analyses of candidate dyslexia and speech/language disorder genes were not significant. These findings contribute to the assessment of genetic associations in reading and language disorders, crucial for understanding their etiology and informing intervention strategies, and validate the approach of using unselected adult samples for gene discovery in language and reading.
\end{abstract}

Keywords: Dyslexia; developmental speech and language disorder; DLD; reading ability; language ability; FOXP2

(Received 13 November 2019; accepted 12 February 2020; First Published online 6 April 2020)

Reading ability is critical for achievement in school, which in turn impacts on success in adulthood (Ritchie \& Bates, 2013). Both impairments and normal variability in reading and language capabilities are highly heritable (Bates et al., 2004; Harlaar et al., 2005), but little is known about the genetic architecture underlying these complex traits. Identifying the key genetic factors that contribute is important for understanding the etiology of reading and language disorders and therefore informing intervention strategies. A key to progress in molecular understanding is increased sample size of study cohorts. To date, most data in language disorder have come from affected samples, often of school age. These samples are modest in size, limiting power. By contrast, large genotyped samples of thousands of unselected adults are now being accumulated (e.g. UK Biobank), although collection of data on reading/ language-related skills has seldom been prioritized. Here, we report

Authors for correspondence: Catherine Doust, Email: s1571212@sms.ed.ac.uk and Michelle Luciano, Email: michelle.luciano@ed.ac.uk

Cite this article: Doust C, Gordon SD, Garden N, Fisher SE, Martin NG, Bates TC, and Luciano M. (2020) The Association of Dyslexia and Developmental Speech and Language Disorder Candidate Genes with Reading and Language Abilities in Adults. Twin Research and Human Genetics 23: 23-32, https://doi.org/10.1017/thg.2020.7 the results of phenotyping a range of reading, spelling and language measures in an unselected adult sample of $>1000$ people, followed by testing for replication of prior associations, to validate this approach for future, large-scale studies of language-related traits and associated disorders.

A number of candidate genes for dyslexia and developmental language disorder (DLD; previously known as specific language impairment or SLD) have been identified through linkage mapping and targeted association (e.g. Francks et al., 2004; Meng et al., 2005; Nopola-Hemmi et al., 2001) and replicated in genetic association studies of children, adolescents and young adults (e.g. Bates et al., 2007; Bates et al., 2010; Scerri et al., 2011). However, many hundreds of quantitative trait loci (QTL) of small effect size $(<1 \%)$ are likely to contribute to these complex, heterogeneous disorders, and much of the relevant genetic variance still remains unaccounted for (Bishop, 2015; Carrion-Castillo et al., 2013; Deriziotis \& Fisher, 2017). Higher powered genome-wide association (GWA) studies derived from larger cohorts are needed to provide further validations of known candidates and to increase sensitivity for identifying new QTL.

Unselected adult cohorts are often orders of magnitude larger than even the largest case-control studies of children. Because

(C) The Author(s) 2020. This is an Open Access article, distributed under the terms of the Creative Commons Attribution licence (http://creativecommons.org/licenses/by/4.0/), which permits unrestricted re-use, distribution, and reproduction in any medium, provided the original work is properly cited. 
specific reading and language impairments are theoretically viewed as the extreme end of a continuum of normally varying ability (Leonard, 1991; Rodgers, 1983), selecting samples from the general population should remain sensitive for detecting relevant genetic factors - an expectation borne out in research on normal adolescents for both dyslexia and poor reading skill (e.g. Lind et al., 2010). Cognitive abilities have been shown to remain stable throughout life (Deary et al., 2000), and reading comprehension measured in adolescents explains $\sim 80 \%$ of the variance in adult reading comprehension (Smith, 1993). Measures of reading ability taken even in adulthood may be as informative as adolescent measures. As maximal reading skill is not reached until the mid-20s, perhaps involving similar mechanisms to those that underlie increasing heritability of intelligence after childhood (McArdle et al., 2002), adult cohorts may provide even more sensitive tests of genetic (as opposed to environmental) variation than do child cohorts. It is currently not known whether general reading ability in adults is underpinned by the same genetic factors as in children with dyslexia.

To probe the utility of unselected adult cohorts, Luciano et al. (2018) tested a set of 14 dyslexia candidate genes originally associated with reading disability in children in a meta-analysis of two cohorts of older adults (mean age $=79$ years). They found that the gene set was significantly associated with a reading index $(p=.016)$ and that individual single nucleotide polymorphism (SNP) associations, although not significant, had allelic effects in the same direction as earlier studies. These results suggest that the same genetic factors underlying reading disability in children may contribute to variation in the normal range of reading ability in later life. However, the measures used to create the reading index in the unselected adults were not ideal. Specifically, Luciano et al. (2018) employed only two word recognition tests: the National Adult Reading Test (Nelson \& Willison, 1991) and the Wechsler Test of Adult Reading (Holdnack, 2001), which both require pronunciation of irregular words. Performance on such tests is strongly influenced by vocabulary size, and since the latter is correlated with intelligence quotient (IQ), with these tasks it is hard to disentangle reading skill from general cognitive ability (Dykiert \& Deary, 2013). Here, we report an association analysis of the same set of candidate genes in an unselected Australian adult sample using validated reading and language measures, including nonword reading to assess phonological processing, a core component of reading skill.

Our strategy for the present study was to identify adults who had already been genotyped across the genome in the context of earlier genome-wide association studies (GWAS) and to perform targeted phenotyping with reading, spelling and language measures. There were three main aims for the research: (1) to demonstrate the reliability and validity of the reading, spelling and language measures (see Table 1) in adults since such studies are uncommon; (2) to confirm in a middle-aged sample (mean $=58.7$ years) that while skill may vary with age such variation is not a significant issue for gene finding and (3) to demonstrate the validity of using unselected adults to identify genetic factors associated with reading and language abilities.

Our long-term goal is to contribute to large-scale GWAS metaanalyses of speech, language and reading skills, given that genomic studies of these phenotypes are lagging behind those of other genetically complex traits (Deriziotis \& Fisher, 2017). Since the cohort described here by itself lacks power for fully genome-wide investigations, for the current study, we focused attention on the most prominent genetic associations from the prior literature. Specifically, we analyzed a set of 14 genes that have been reported to show associations with dyslexia - CMIP, CNTNAP2, CYP19A1, DCDC2, DIP2A, DXY1C1, GCFC2 (or C2orf3), KIAA0319, KIAA0319L, MRPL19, ROBO1, PCNT, PRMT2 and S100B (see Luciano et al., 2018, for rationale). We also analyzed a set of five genes previously associated with language disorders of various kinds - ATP2C2, CMIP, CNTNAP2, FOXP2 and TM4SF20. The rationale for selecting these five genes is as follows. Studies of nonword repetition in a DLD cohort collected by the UK SLI Consortium identified associations with SNPs in ATP2C2 and CMIP (Newbury et al., 2009) as well as in CNTNAP2 (Vernes et al., 2008). Nonword repetition was chosen for those studies (and also the present work) since it is a measure of phonological short-term memory that is often impaired in DLD (Gathercole et al., 1994; Newbury et al., 2005). Mutations in the FOXP2 gene have been reported to segregate with severe speech and language disorders, mainly characterized by childhood apraxia of speech, in a large family pedigree (Lai et al., 2001), and additional FOXP2 mutations have been found in independent cases with similar impairments (Morgan et al., 1993). TM4SF20 was associated with early language delay in Southeast Asian families (Wiszniewski et al., 2013). In addition to analyses of the gene sets as a whole, we examined individual SNPs from within the relevant candidate genes that were previously reported to be associated with reading/ language ability or impairment.

Finally, we included as a target the axon guidance pathway (GO:0007411: 'chemotaxis process that directs the migration of an axon growth cone to a specific target site'; 216 genes) and the neuron migration pathway (GO:0001764: 'movement of an immature neuron from germinal zones to specific positions where they will reside as they mature'; 214 genes) which have both been suggested to be implicated in dyslexia (Poelmans et al., 2011), although see Guidi et al. (2018) for a critical review.

\section{Materials and Methods}

\section{Participants}

In 2017, we recruited participants from earlier twin studies at the QIMR Berghofer Medical Research Institute in Australia. The final cohort consisted of 1550 participants (78.06\% female), 1505 of whom had previously been genome-wide genotyped using SNP arrays and were living in Australia. Ages ranged from 41.7 to 73.2 years $($ mean $=58.7, S D=7.8$ ). Self-report data on dyslexia, DLD and related traits were collected in all 1505 participants (including 227 sibling pairs, 76 of whom were monozygotic (MZ) twins). Reading and language test data were collected in 1112 participants (including 197 sibling pairs and $70 \mathrm{MZ}$ twins). All participants were free from neurological conditions and major psychiatric illness at the time of testing.

\section{Genotyping}

Participants had been genotyped on standard Illumina SNP arrays, the chip model varying, and merged after quality control (QC; including Mendelian checks, as data are typically family based). Within each batch, and across batches, sample errors or failures were identified using sex and relatedness tests, and either corrected or removed as appropriate. Samples were also removed if they were below a $97 \%$ call rate or (at a later stage post-merging) of nonEuropean ancestry as judged from nonclustering with known European populations in a principal component analysis (PCA). Markers in a batch were dropped due to Illumina-recommended QC filters (e.g. GenTrain score), as well as: (1) there were issues 
Table 1. Full assessment battery administered to the Brisbane adult cohort

\begin{tabular}{|c|c|c|}
\hline Measure & Test details/response options & Purpose \\
\hline $\mathrm{CC} 2 \mathrm{~A}$ & $\begin{array}{l}\text { Reading and correct pronunciation of } 55 \text { regular } \\
\text { and } 55 \text { irregular words and } 55 \text { nonwords }\end{array}$ & $\begin{array}{l}\text { Regular word reading assesses general reading } \\
\text { skill } \\
\text { Irregular word reading assesses lexical reading } \\
\text { only } \\
\text { Nonword reading assesses phonological } \\
\text { processing only }\end{array}$ \\
\hline Spelling & Spell 36 regular and irregular words & $\begin{array}{l}\text { Regular word spelling assesses general spelling } \\
\text { skill } \\
\text { Irregular word spelling specifically assesses } \\
\text { lexical spelling skill }\end{array}$ \\
\hline Phonetic spelling & Spell 18 regular and irregular words 'as it sounds' & Assesses non-lexical spelling skill \\
\hline $\begin{array}{l}\text { Gathercole and Baddeley Nonword } \\
\text { Repetition Test }\end{array}$ & $\begin{array}{l}\text { Repeat } 40 \text { nonwords of } 2,3,4 \text { or } 5 \text { syllables back to the } \\
\text { interviewer }\end{array}$ & $\begin{array}{l}\text { Assesses the phonological loop, a component } \\
\text { of learning language }\end{array}$ \\
\hline Self-reported book reading & $\begin{array}{l}\text { Frequency of reading books (not newspapers or } \\
\text { magazines): daily, weekly, monthly, yearly or never }\end{array}$ & Correlates with reading ability (Smith, 1996) \\
\hline $\begin{array}{l}\text { Self-reported reading or language } \\
\text { difficulties }\end{array}$ & $\begin{array}{l}\text { Yes/no } \\
\text { If yes, was it self-evaluated or noticed by others, } \\
\text { and what is the formal diagnosis (if any)? }\end{array}$ & \\
\hline Child with reading or language difficulties & $\begin{array}{l}\text { Yes/no } \\
\text { If yes, was it self-evaluated or noticed by others, } \\
\text { and what is the formal diagnosis (if any)? }\end{array}$ & \\
\hline Age & Years & Covariates \\
\hline Sex & Female/male & \\
\hline School years & $\begin{array}{l}\text { Highest year of school completed (year } 6 \text { and below to } \\
\text { year 12) }\end{array}$ & \\
\hline Higher education & Yes/no & \\
\hline Qualifications & Any obtained & \\
\hline Self-estimated IQ & $\begin{array}{l}\text { Do not know/well below average/low average/average/ } \\
\text { high average/superior/very superior }\end{array}$ & \\
\hline Hearing difficulties & Yes/no & \\
\hline Stutter & Yes/no & \multirow{12}{*}{$\begin{array}{l}\text { May share genetic etiology with reading and } \\
\text { language abilities }\end{array}$} \\
\hline Developmental delay & Yes/no & \\
\hline Dyspraxia & Yes/no & \\
\hline ASD & Yes/no & \\
\hline Attention deficit hyperactivity disorder & Yes/no & \\
\hline Tourette syndrome & Yes/no & \\
\hline Eating disorder & Yes/no & \\
\hline Obsessive-compulsive disorder & Yes/no & \\
\hline Depression & Yes/no & \\
\hline Bipolar disorder & Yes/no & \\
\hline Social anxiety & Yes/no & \\
\hline Personality disorder & Yes/no & \\
\hline
\end{tabular}

$\mathrm{CC} 2 \mathrm{~A}=$ Castles and Coltheart Test 2 Adults, $\mathrm{IQ}=$ intelligence quotient, $\mathrm{ASD}=$ Autism Spectrum Disorder.

with map placement or strand alignment in a Basic Local Alignment Search Tool search of primers; (2) call rate was $<95 \%$; (3) $p<1 \times 10^{-6}$ in Hardy-Weinberg equilibrium tests; (4) minor allele frequency (MAF) was $<1 \%$; (5) (for chromosome X) male heterozygosity $<\%$; (6) for older chips, there was a low mean GenCall score, $<0.7$ (Duffy et al., 2018; Medland et al., 2009).

Data were imputed to the Haplotype Reference Consortium reference panel version r1.1 (Haplotype Reference Consortium et al., 2016) and SNPs with a MAF of $<.05$ and an imputation accuracy of $<.8$ were excluded. Imputed genotypes were taken from three imputation runs (each using Eagle for phasing and minimac3 (autosomes) or minimac4 (chromosome X) for imputation, on the University of Michigan Imputation Server). Each run used individuals genotyped in a specific chip family, one of (1) the oldest HapMap-based Illumina chips; (2) GSA chips; (3) Omni and Core+Exome/PsychArray chips; and observed markers passing QC for all corresponding batches of genotyping. The three imputation runs were then merged by taking (for each individual) preferentially (1), (2) or (3) in that order (as this generally corresponds to the best-quality imputation). 
The breakdown of chip models is (1) HapMap-based: 610 K-quad $(n=427), 660 \mathrm{~K} / 670 \mathrm{~K}$-quad $(n=213)$, CNV370 $(n=399)$, $317 \mathrm{~K}(n=63)$; (2) GSA: GSA Avera $(n=2)$; (3) Core+Exome $(n=152)$, PsychArray $(n=65)$, Omni2.5 $(n=34)$, OmniExpress $(n=4)$.

\section{Measures and Procedure}

An approach email was sent to participants with a link to the detailed information sheet and online consent form. They were then directed to a brief self-report questionnaire, which included education, how frequently they read books (excluding magazines and newspapers), their estimated IQ, whether or not they or their child has a reading or language disorder and whether or not they have a range of other behavioral or psychiatric conditions (Table 1). Within two weeks of completion of this survey, eligible participants who provided informed online consent were contacted for a telephone interview. At the time of the interview, participants were then emailed an online link to access the tests.

Three tests were administered: the Castles and Coltheart Test 2 Adults (CC2A) reading test (Castles \& Coltheart, 1993), the Gathercole and Baddeley Nonword Repetition Test (Gathercole et al., 1994) and a spelling test, including phonetic spelling (Table 1). CC2A requires the reading aloud and correct pronunciation of 55 each of regular words, irregular words and nonwords. Irregular word reading assesses the lexical route of reading while nonword reading specifically assesses phonological processing. Similarly, our spelling test includes 22 regular and 14 irregular words plus a phonetic spelling task to spell 18 irregular words 'as they sound' to assess phonological processing. Gathercole et al.'s (1994) task of nonword repetition measures language ability as related to phonological encoding and memory. Data for one individual with 10 missing items were excluded from the nonword repetition task.

\section{Statistical Analyses}

Multiple regression was used to predict each of the reading, spelling and language outcome measures from age, sex and hearing difficulties. Hearing difficulties included any respondent who reported hearing difficulties or use of a hearing aid, or any respondent identified as having hearing difficulties by the interviewer. We used residual scores in further analyses. A unitary reading and spelling ability measure was created based on the scores on the first principal component (PC) of a PCA of the regular and irregular word and nonword reading, and regular, irregular and phonetic word spelling measures.

GWA results were generated for each of five variables (the reading and spelling PC, nonword reading, phonetic spelling, nonword repetition and self-reported reading impairment). This was undertaken using the Genome-wide Complex Trait Analysis software (Yang et al., 2011), which can account for family relatedness. Where more than one member of an MZ twin pair had been assessed, only one member was selected at random for the analyses, with final genetic association samples of 1425 for self-reported reading impairment, 1290 for the reading and spelling PC, 1293 for nonword reading and 1292 for phonetic spelling and nonword repetition.

Using the available summary statistics from the above, gene-set analysis was performed for four gene sets: dyslexia candidate genes $(N=14)$, speech/language disorder candidate genes $(N=5)$, the axon guidance pathway (gene ontology (GO) term GO:0007411; 216 genes) and the neuron migration pathway (GO:0001764;
145 genes). Individual gene-based analysis was also performed for genes within the dyslexia and speech/language disorder candidate sets. Bonferroni correction derived a critical $p$ value of .003 . Analyses were performed using MAGMA (de Leeuw et al., 2015) to test for overrepresentation of significantly associated SNPs within each set and within each candidate gene. Bonferroni correction for multiple testing was too conservative because the candidate gene sets wholly overlapped with the biological pathway gene sets, so an effective number of independent tests of 2 were used to derive an adjusted critical $p$ value of .025 .

Within the candidate gene sets, 77 SNPs had previously been associated with reading or language ability or disability, or were variants identified through fluorescence in situ hybridization and SNP microarray analysis of a small deletion at 21q22.3 segregating with dyslexia in a family (see Supplementary Material). A total of 68.7 independent tests were derived through matrix spectral decomposition, taking into account linkage disequilibrium (Nyholt, 2004). Bonferroni correction gave an adjusted $\alpha$ level of $7.28 \times 10^{-4}$.

\section{Results}

\section{Phenotypic Analyses}

The distributions of the raw reading, spelling and language test scores were slightly negatively skewed. We used multiple regression to predict each of the outcome measures from age, sex and hearing difficulties (Supplementary Table S1) with the resulting residual scores (used for genetic association analysis) normally distributed. The multiple regression results indicate that age-squared was only a significant predictor for nonword repetition $(\beta=-0.00$, $p=.042)$. Females scored higher than males for regular word reading $(\beta=-0.45, p=.006)$, nonword repetition $(\beta=-0.96$, $p=.004)$, regular word spelling $(\beta=-0.03, p<.001)$ and irregular word spelling $(\beta=-0.61, p<.001)$. Hearing difficulties were associated with worse irregular word reading $(\beta=-1.36, p=.029)$, nonword reading $(\beta=-3.23, p<.001)$, nonword repetition $(\beta=-0.96, p=.004)$ and regular word spelling $(\beta=-0.04$, $p=.023)$ performance. Outliers were set to a trimmed minimum of negative four standard deviations.

Table 2 shows a correlation matrix of raw reading, spelling and language scores and covariates. Minimum and maximum values, means and standard deviations for each of the variables are in Table 3, while Table 4 gives the frequencies of discrete variables. Frequent book reading correlates with higher scores on reading and spelling tasks but not with nonword repetition. More years at school is correlated with higher scores in all reading, spelling and language tasks. Self-report of a reading impairment is associated with lower scores in reading and spelling tasks but bears no relationship with nonword repetition. Self-reported language impairments do not correlate with any task, including nonword repetition.

In the PCA of reading and spelling scores, a scree plot of the eigenvalues shows the first PC is sufficient to explain the majority of variation $(63.1 \%)$ in reading and spelling skills (Supplementary Figure S1).

\section{Genetic Association Results}

Quantile-quantile plots of the expected distribution of $p$ values across SNPs within the dyslexia and speech/language disorder candidate gene sets (Supplementary Figure S2) demonstrate a slight positive deviation from the null distribution, indicative of genetic 
Table 2. Intercorrelations (Pearson's $r$ ) between reading, spelling and language measures and covariates

\begin{tabular}{|c|c|c|c|c|c|c|c|c|c|c|c|c|c|c|}
\hline Measure & 1 & 2 & 3 & 4 & 5 & 6 & 7 & 8 & 9 & 10 & 11 & 12 & 13 & 14 \\
\hline 1. Age $(n=1550)$ & - & & & & & & & & & & & & & \\
\hline 2. $\operatorname{Sex}(n=1550)$ & $.10^{*}$ & - & & & & & & & & & & & & \\
\hline 3. School years $(n=1550)$ & $-.07 *$ & $.05^{*}$ & - & & & & & & & & & & & \\
\hline 4. Book reading $(n=1550)$ & $.08^{*}$ & $-.14 *$ & $.11^{*}$ & - & & & & & & & & & & \\
\hline 5. Reading impairment $(n=1520)$ & -.04 & .04 & $-.06^{*}$ & $-.14 *$ & - & & & & & & & & & \\
\hline 6. Language impairment $(n=1470)$ & -.02 & .00 & -.02 & .01 & .04 & - & & & & & & & & \\
\hline 7. Hearing difficulties $(n=1532)$ & $.09 *$ & $.06 *$ & $-.06^{*}$ & -.01 & .02 & .00 & - & & & & & & & \\
\hline 8. Regular reading $(n=1386)$ & $.06 *$ & $-.07^{*}$ & $.15^{*}$ & $.25 *$ & $-.28^{*}$ & $-.09 *$ & -.03 & - & & & & & & \\
\hline 9. Irregular reading $(n=1386)$ & $.10 *$ & -.03 & $.20 *$ & $.26 *$ & $-.23 *$ & $-.07 *$ & -.05 & $.61^{*}$ & - & & & & & \\
\hline 10. Nonword reading $(n=1386)$ & .02 & -.04 & $.16^{*}$ & $.20 *$ & $-.30 *$ & $-.09 *$ & $-.09 *$ & $.69 *$ & $.61^{*}$ & - & & & & \\
\hline 11. Regular spelling $(n=1384)$ & $.14^{*}$ & $-.10 *$ & $.15^{*}$ & $.26 *$ & $-.26 *$ & $-.06 *$ & $-.06 *$ & $.56^{*}$ & $.53 *$ & $.57 *$ & - & & & \\
\hline 12. Irregular spelling $(n=1376)$ & $.07^{*}$ & $-.13^{*}$ & $.13^{*}$ & $.25^{*}$ & $-.34 *$ & -.04 & -.02 & $.59 *$ & $.56^{*}$ & $.59 *$ & $.64 *$ & - & & \\
\hline 13. Phonetic spelling $(n=1385)$ & .04 & -.02 & $.15^{*}$ & $.11^{*}$ & $-.17 *$ & $-.06 *$ & -.04 & $.50 *$ & $.40 *$ & $.62 *$ & $.45^{*}$ & $.41^{*}$ & - & \\
\hline 14. Reading and spelling PC $(n=1345)$ & .00 & .00 & $.20 *$ & $.26 *$ & $-.33 *$ & $-.09 *$ & .00 & $.83^{*}$ & $.78^{*}$ & $.86^{*}$ & $.77^{*}$ & $.79 *$ & $.70 *$ & - \\
\hline 15. Nonword repetition $(n=1385)$ & $-.15^{*}$ & $-.10 *$ & $.11^{*}$ & $.08 *$ & .00 & -.02 & $-.28 *$ & $.19 *$ & $.22 *$ & $.26^{*}$ & $.21^{*}$ & $.14^{*}$ & $.22 *$ & $.25^{*}$ \\
\hline
\end{tabular}

Note: Correlations are not adjusted for case nonindependence.

$\mathrm{PC}=$ principal component.

${ }^{\star} p \leq .05$; sex (males), impairment and hearing difficulties are coded positively.

Table 3. Summary statistics of the main continuous variables including reading, spelling and language measures

\begin{tabular}{lccc}
\hline Variable & Minimum & Mean (SD) & Maximum \\
\hline Regular word reading & 70.91 & $95.19(4.55)$ & 100.00 \\
\hline Irregular word reading & 50.91 & $85.31(7.75)$ & 100.00 \\
\hline Nonword reading & 24.07 & $83.78(12.49)$ & 100.00 \\
\hline Regular word spelling & 28.57 & $90.09(10.57)$ & 100.00 \\
\hline Irregular word spelling & 21.43 & $89.90(12.89)$ & 100.00 \\
\hline Phonetic spelling & 0.00 & $71.08(20.13)$ & 100.00 \\
\hline Nonword repetition & 0.00 & $75.57(13.04)$ & 100.00 \\
\hline Age & 41.69 & $58.70(7.79)$ & 73.19 \\
\hline School years & 0.00 & $11.18(1.81)$ & 12.00 \\
\hline
\end{tabular}

Note: For reading, spelling and language scores, summary statistics are calculated from the percentage of correct items.

signal, for phonetic spelling for dyslexia candidate gene subset of SNPs (Supplementary Figure S2(b)) and for nonword repetition for both dyslexia and speech/language disorder candidate gene SNP subsets (Supplementary Figure S2(e) and (f)). In gene-based analyses (Table 5), FOXP2 was associated with nonword repetition $(p<.001)$, phonetic spelling $(p=.002)$ and the reading and spelling composite score $(p<.001)$, withstanding a corrected $\alpha$ level of .003 . For nonword repetition, FOXP2 was in the top three most significant genes.

Gene-set analysis of the neuron migration pathway revealed a nominal association with the reading and spelling composite score ( $p=.037$; Table 6), which did not survive correction for multiple testing, and gene-set analyses of 14 candidate dyslexia genes, five candidate speech/language disorder genes and the axon guidance pathway were also not significant.

Of the SNPs within the dyslexia and speech/language disorder candidate gene sets, 77 have previously been reported to be associated with reading or language ability or impairment (Supplementary Tables S2-S6). None were close to the corrected significance level of $p<7.28 \times 10^{-4}$.

\section{Discussion}

In this study, we introduced a new population sample of previously genotyped adults for whom we have recently obtained reading and language measures. Our aim was to determine the validity of using unselected adults to identify genetic factors associated with reading and language abilities. We demonstrate the suitability of the reading and language measures to determine ability among unimpaired adults, and we confirm that age is not a confounder. Notably, there was no association between age and the most sensitive index of reading skill, namely phonological decoding (assessed through nonword reading). In our adult population, we observed associations at the gene-based level for candidate genes that have previously been implicated in dyslexia or speech/language disorders in children and adolescents; for example, finding that variation in FOXP2 (a gene implicated in a monogenic form of speech apraxia) was associated with nonword repetition. Further, in gene pathway analyses, we find some support for associations of genes involved in neuronal migration with reading skill, albeit at a nominal level of significance that does not survive multiple-testing adjustment.

Establishing sensitive measures of adult reading and language abilities is crucial because individuals with an impairment may develop coping strategies over the life course. We demonstrated that the CC2A reading task and our spelling task, which included reading nonwords and phonetic spelling, correlate with how often individuals read books. Reading books, more so than other forms of print, is associated with higher literacy proficiency (Smith, 1996). Further, performance on the reading, spelling and language measures correlated with the number of school years individuals completed, supporting the known association between educational achievement and reading and language abilities (Garnier et al., 
Table 4. Percentage frequencies of major discrete variables

\begin{tabular}{lc}
\hline Variable & Frequency (\%) \\
\hline Sex & \\
\hline Female & 78.06 \\
\hline Male & 21.94 \\
\hline Higher education & 84.38 \\
\hline Frequency of book reading & \\
\hline Daily & 29.29 \\
\hline Weekly & 15.42 \\
\hline Monthly & 13.55 \\
\hline Yearly & 29.55 \\
\hline Never & 12.19 \\
\hline Hearing difficulties & 1.50 \\
\hline Reading impairment & 5.26 \\
\hline Reading impairment evaluation & \\
\hline Self-evaluated & 40.00 \\
\hline Noticed by others (e.g. teachers) & 53.75 \\
\hline Clinically diagnosed & 6.25 \\
\hline Child with reading impairment & 5.89 \\
\hline Stutter & 21.43 \\
\hline No & 2.65 \\
\hline Sometimes & 39.21 \\
\hline Yes & 39.29 \\
\hline Other language impairment & \\
\hline Language impairment evaluation & \\
\hline Self-evaluated & \\
\hline Noticed by others (e.g. teachers) & \\
\hline Clinically diagnosed & \\
\hline Child with language impairment & \\
\hline & \\
\hline
\end{tabular}

1997; Snowling et al., 2001). We also found that the reading and spelling scores in our cohort correlated with whether individuals self-reported a reading impairment but not with self-report of a language impairment. Unexpectedly, nonword repetition scores showed no relationship to self-report of a language impairment, even though individuals with DLD are less able to acquire phonological forms of new words (Gathercole, 2006; Newbury et al., 2005). We may be statistically underpowered to detect a relationship due to the low frequency of reports of language impairments $(1.9 \%)$ in our modestly sized cohort, and as such this could be a type II error. Alternatively, this result may reflect an ascertainment bias in addition to the unreliability of self-reported measures for accurately measuring true frequencies of learning disabilities, particularly considering historical context: the youngest members of this cohort were born in 1975, six years before a standard set of criteria for diagnosing DLD (formerly known as SLI) existed (Stark \& Tallal, 1981). The population frequency of language deficits not attributable to hearing impairment, low nonverbal intelligence or neurological damage is estimated to be closer to $7 \%$ (Leonard, 2014).

In gene-based analyses of prior candidate genes from the dyslexia and speech/language disorder literature, we identified associations with several reading, spelling and language measures in our cohort of largely unimpaired adults. A discussion of the individual SNP results can be found in the Supplementary Material. Variation in FOXP2 was associated with nonword repetition as well as phonetic spelling, and a reading/spelling composite score. FOXP2 (Forkhead Box P2) encodes a transcription factor involved in the development of the brain (among other tissues) and acts through regulating hundreds of genes (Fisher \& Scharff, 2009). The gene was first identified through positional cloning studies of a severe speech and language disorders involving childhood apraxia of speech in a large multigenerational pedigree (Fisher et al., 1998). All affected cases in this family were found to carry a missense mutation in the DNA-binding domain of the encoded protein, and a translocation disrupting FOXP2 was discovered in an unrelated individual with a similar disorder (Lai et al., 2001). Subsequently, additional rare protein-coding changes (including both missense and nonsense mutations) have been identified as causes of developmental speech and language disorders in multiple independent families and cases (MacDermot et al., 2005; Morgan et al., 1993; Reuter et al., 2017). Despite robust evidence implicating rare disruptions of FOXP2 in severe speech and language deficits across independent studies, the contributions of common variation in this gene to language-related phenotypes remain open to debate (see Uddén et al., 2019). For example, in one of the largest prior studies to assess this issue, Mueller et al. (2016) tested for a relationship of 13 SNPs in FOXP2 and language ability in a modestly sized population cohort of children $(N=812)$ and found no significant associations. Given our contradictory findings in the present study, further investigations using robust measures in larger samples of adults and children are warranted to resolve this long-standing question. Of note, in a recent meta-GWAS of $>20 \mathrm{k}$ individuals diagnosed with attention deficit/hyperactivity disorder (ADHD) compared to $>35 \mathrm{k}$ controls, SNPs in FOXP2 were among the top genome-wide significant hits, which is intriguing in light of the known overlaps between $\mathrm{ADHD}$ and reading disabilities (Demontis et al., 2019).

ATP2C2 (ATPase secretory pathway $\mathrm{Ca}^{2+}$ transporting 2) catalyzes ATP hydrolysis coupled with calcium transportation. The gene was identified as a candidate for involvement in DLD susceptibility by the SLI Consortium (2002) following an early linkage study of families with DLD probands that included nonword repetition as a quantitative measure. In targeted analyses of the linkage region, SNPs in ATP2C2 were found to be associated with both nonword repetition and reading measures in language-impaired individuals, but not in an unselected cohort (Newbury et al., 2011; Newbury et al., 2009). In the present study, we detected association of ATP2C2 with nonword repetition, phonetic spelling, nonword reading and the reading/spelling composite score, although the significance levels were not robust to multiple-testing adjustment.

We also detected nominally significant associations of the dyslexia candidate genes MRPL19 (with phonetic spelling) and $S 100 B$ (with nonword repetition). MRPL19 (mitochondrial ribosomal protein L19) encodes a ribosomal subunit and is involved in protein synthesis. A risk haplotype in a locus containing MRPL19 and C2ORF3 was associated with dyslexia in Finnish families and replicated in a German sample (Anthoni et al., 2007). Heterozygous carriers of the risk haplotype had reduced expression of both genes. MRPL19 expression correlates with that of dyslexia candidate genes DCDC2, DYX1C1, KIAA0319 and ROBO1; however, the NeuroDys study of 900 individuals with dyslexia across eight countries failed to replicate the effects of MRPL19 (Becker et al., 2014). 
Table 5. Gene-based analysis of dyslexia and speech/language disorder candidate genes for association with measures of reading, spelling and language

\begin{tabular}{|c|c|c|c|c|c|c|c|c|c|c|c|c|c|}
\hline \multirow[b]{2}{*}{ Gene set } & \multirow[b]{2}{*}{ Gene } & \multirow[b]{2}{*}{$\mathrm{Chr}$} & \multirow[b]{2}{*}{ SNPs (n) } & \multicolumn{2}{|c|}{$\begin{array}{l}\text { Nonword } \\
\text { reading }\end{array}$} & \multicolumn{2}{|c|}{$\begin{array}{l}\text { Phonetic } \\
\text { spelling }\end{array}$} & \multicolumn{2}{|c|}{$\begin{array}{l}\text { Reading and } \\
\text { spelling PC }\end{array}$} & \multicolumn{2}{|c|}{$\begin{array}{l}\text { Self-reported } \\
\text { reading } \\
\text { impairment }\end{array}$} & \multicolumn{2}{|c|}{$\begin{array}{l}\text { Nonword } \\
\text { repetition }\end{array}$} \\
\hline & & & & $z$ & $p$ & $z$ & $p$ & $z$ & $p$ & $z$ & $p$ & $z$ & $p$ \\
\hline \multirow{8}{*}{ Dyslexia } & KIAA0319L & 1 & 11 & 0.08 & .47 & 0.31 & .38 & -0.34 & .63 & -0.98 & .84 & -0.87 & .81 \\
\hline & GCFC2 & 2 & 81 & 0.37 & .36 & 1.62 & .053 & 0.33 & .37 & 0.013 & .49 & 0.76 & .22 \\
\hline & MRPL19 & 2 & 38 & 0.54 & .29 & 1.86 & .031 & 0.75 & .23 & 0.15 & .44 & 1.23 & .11 \\
\hline & $D C D C 2$ & 6 & 467 & 0.54 & .29 & -0.43 & .66 & 1.19 & .12 & -1.55 & .94 & 1.38 & .08 \\
\hline & KIAA0319 & 6 & 210 & -0.59 & .72 & 1.25 & .11 & -0.77 & .78 & 0.22 & .41 & -1.03 & .85 \\
\hline & CYP19A1 & 15 & 217 & -0.54 & .71 & -0.35 & .64 & 0.71 & .24 & -0.62 & .73 & -0.23 & .59 \\
\hline & $D Y X 1 C 1$ & 15 & 204 & 0.61 & .27 & 1.01 & .16 & 0.31 & .38 & 0.40 & .35 & -0.092 & .54 \\
\hline & $S 100 B$ & 21 & 25 & -0.90 & .82 & 1.03 & .15 & 1.51 & .065 & 0.89 & .19 & 1.69 & .046 \\
\hline \multirow{2}{*}{$\begin{array}{l}\text { Dyslexia and speech/ } \\
\text { language disorders }\end{array}$} & CNTNAP2 & 7 & 5389 & 0.028 & .49 & -0.41 & .66 & -1.21 & .89 & -0.52 & .70 & -1.93 & .97 \\
\hline & CMIP & 16 & 736 & -0.23 & .59 & -0.27 & .61 & -2.45 & .99 & 0.39 & .35 & -0.95 & .83 \\
\hline \multirow[t]{3}{*}{ Speech/language disorders } & TM4SF20 & 2 & 49 & -1.13 & .87 & -0.35 & .64 & -1.13 & .87 & -0.74 & .77 & -1.09 & .86 \\
\hline & FOXP2 & 7 & 547 & 0.44 & .33 & 2.94 & .002 & 3.78 & $<.001$ & -0.46 & .68 & 3.67 & $<.001$ \\
\hline & ATP2C2 & 16 & 494 & 2.23 & .013 & 1.67 & .048 & 1.74 & .041 & -0.20 & .58 & 2.19 & .014 \\
\hline
\end{tabular}

Note: Bold type indicates nominal significance.

$\mathrm{Chr}=$ chromosome.

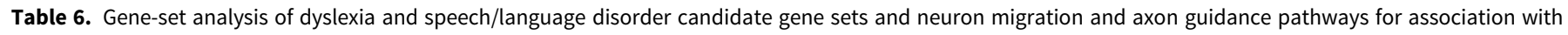
measures of reading, spelling and language

\begin{tabular}{|c|c|c|c|c|c|}
\hline Gene set & Variable & $B$ & $\beta$ & SE & $p$ \\
\hline \multirow{5}{*}{ Dyslexia candidates $(N=14)$} & Nonword reading & -0.14 & -0.00 & 0.23 & .73 \\
\hline & Nonword repetition & 0.08 & 0.00 & 0.24 & .37 \\
\hline & Phonetic spelling & 0.14 & 0.00 & 0.23 & .28 \\
\hline & Reading and spelling PC & -0.26 & -0.01 & 0.24 & .86 \\
\hline & Self-reported reading impairment & 0.09 & 0.00 & 0.23 & .35 \\
\hline DLD candidates $(N=5)$ & Nonword repetition & -0.01 & -0.00 & 0.36 & .51 \\
\hline \multirow[t]{5}{*}{ Neuron migration pathway $(N=145)$} & Nonword reading & 0.06 & 0.01 & 0.08 & .21 \\
\hline & Nonword repetition & -0.05 & -0.00 & 0.08 & .72 \\
\hline & Phonetic spelling & 0.04 & 0.00 & 0.08 & .31 \\
\hline & Reading and spelling PC & 0.14 & 0.01 & 0.08 & .037 \\
\hline & Self-reported reading impairment & 0.08 & 0.01 & 0.08 & .13 \\
\hline \multirow[t]{5}{*}{ Axon guidance pathway $(N=216)$} & Nonword reading & -0.04 & -0.00 & 0.06 & .73 \\
\hline & Nonword repetition & 0.00 & 0.00 & 0.06 & .47 \\
\hline & Phonetic spelling & -0.05 & -0.10 & 0.06 & .82 \\
\hline & Reading and spelling PC & 0.04 & 0.00 & 0.06 & .26 \\
\hline & Self-reported reading impairment & 0.01 & 0.00 & 0.06 & .45 \\
\hline
\end{tabular}

Note: Bold type indicates nominal significance.

$\mathrm{PC}=$ principal component, $\mathrm{DLD}=$ developmental language disorder .

S100B (S100 Calcium Binding Protein B) is involved in neurite outgrowth and neuronal migration (Huttunen et al., 2000; Poelmans et al., 2011) and was identified as one of four genes in a deleted region co-segregating with dyslexia in a family (Poelmans et al.,
2009). A noncoding variant was later associated with spelling in German families (Matsson et al., 2015), but no other studies have identified the gene in association with language ability or impairment. 
An association between genes in the neuron migration pathway and the reading and spelling composite score supports proposals from Galaburda et al. (2006), Paracchini et al. (2007) and Poelmans et al. (2011), who hypothesized that dyslexia candidate genes are part of a molecular network that regulates neuronal migration and neurite outgrowth. A more recent review from Guidi et al. (2018) critically evaluated this hypothesis and suggested that there is a lack of robust evidence supporting the theory. We did not find an association of the neuron migration pathway with any measure other than our composite score, nor was the axon guidance pathway significant in our study. However, the GO terms defining these pathways are incompletely annotated and continue to expand. At the time of publishing a previous paper (Luciano et al., 2018), the neuron migration pathway contained 103 genes and the axon guidance pathway contained 203 genes, in comparison to 145 and 216 genes, respectively, at present. In the previous paper, no significant associations were found for either pathway, but here we detected an association with a reading and spelling score, albeit not robust to correction for multiple testing, highlighting the potential value of continuing to probe these pathways in their possible link to dyslexia as they are annotated with increasing resolution.

Our failure to replicate previous genetic associations may be due to a lack of statistical power to detect genetic variants of small effect size, may represent true null associations and, further, findings from prior studies could be false positives. Here, we had $78.43 \%$ power to find an effect size minimum of 0.005 (calculated using the Genetic Power Calculator; Purcell et al., 2003). Further, our participants were recruited through a twin registry, which may be subject to a sampling bias: frequencies of self-reported reading (5.26\%) and language (1.90\%) impairments were below the estimated population frequencies ( $10 \%$ and $7 \%$, respectively). Variants may have stronger effects at the tail end of ability or in individuals with an impairment, and hence greater statistical power is required to replicate them in unselected populations compared with case-control studies. Future meta-analyses and larger GWA studies of both selected and unselected cohorts of children and adults will enable stronger conclusions to be drawn about the genetic influences on reading acquisition and continuity of reading skill over the life course and their relationship to reading disorder. In this study, we were unable to disentangle general cognitive ability from reading and language skills, which are highly correlated traits. The inclusion of an IQ test as a covariate in future studies would enable better isolation of specific reading and language abilities.

This study introduces an important new population cohort of genotyped adults with validated measures of reading and language abilities. We also measured a self-reported binary status on a range of comorbidities of dyslexia and DLD, including stutters, autism spectrum disorder (ASD) and ADHD. We have shown that at least some candidate genes associated with dyslexia and speech/ language disorders in children and adolescents may show effects in unselected adult populations, demonstrating the potential of such resources (when suitably scaled-up) for the discovery of novel genetic variants associated with reading and language traits. Future studies should aim to conduct large-scale GWA analyses and metaanalyses of unselected adults to identify genetic variants that are associated with measures of reading and language abilities, accounting for general cognitive ability where possible. Analyses of relevant continuous traits in unselected populations generalize to other learning impairments and neurological traits. Ultimately, uncovering the genetic etiology of developmental disorders will enable early diagnosis and appropriate intervention.

Supplementary material. To view supplementary material for this article, please visit https://doi.org/10.1017/thg.2020.7.

Acknowledgments. We would like to thank the research interviewers and the study participants. We are grateful to Marie-Christine Opitz for data cleaning assistance.

Financial support. S.E.F. is supported by the Max Planck Society. Data collection was funded in part by a Centre for Cognitive Ageing and Cognitive Epidemiology Pilot grant.

\section{Conflict of interest. None.}

Ethical standards. The authors assert that all procedures contributing to this work comply with the ethical standards of the relevant national and institutional committees on human experimentation and with the Helsinki Declaration of 1975 , as revised in 2008 .

\section{References}

Anthoni, H., Zucchelli, M., Matsson, H., Muller-Myhsok, B., Fransson, I., Schumacher, J., . . . Peyrard-Janvid, M. (2007). A locus on 2p12 containing the co-regulated MRPL19 and C2ORF3 genes is associated to dyslexia. Human Molecular Genetics, 16, 667-677.

Bates, T. C., Castles, A., Coltheart, M., Gillespie, N., Wright, M., \& Martin, N. G. (2004). Behaviour genetic analyses of reading and spelling: A component processes approach. Australian Journal of Psychology, 56, 115-126.

Bates, T. C., Castles, A., Luciano, M., Wright, M., Coltheart, M., \& Martin, N. G. (2007). Genetic and environmental bases of reading and spelling: A unified genetic dual route model. Reading and Writing, 20, 147-171.

Bates, T. C., Lind, P. A., Luciano, M., Montgomery, G. W., Martin, N. G., \& Wright, M. J. (2010). Dyslexia and DYX1C1: deficits in reading and spelling associated with a missense mutation. Molecular Psychiatry, 15, 1190-1196.

Becker, J., Czamara, D., Scerri, T. S., Ramus, F., Csepe, V., Talcott, J. B., . . . Schumacher, J. (2014). Genetic analysis of dyslexia candidate genes in the European cross-linguistic NeuroDys cohort. European Journal of Human Genetics, 22, 675-680.

Bishop, D. V. (2015). The interface between genetics and psychology: lessons from developmental dyslexia. Proceedings of the Royal Society B, 282, 20143139.

Carrion-Castillo, A., Franke, B., \& Fisher, S. E. (2013). Molecular genetics of dyslexia: an overview. Dyslexia, 19, 214-240.

Castles, A., \& Coltheart, M. (1993). Varieties of developmental dyslexia. Cognition, 47, 149-180.

de Leeuw, C. A., Mooij, J. M., Heskes, T., \& Posthuma, D. (2015). MAGMA: Generalized gene-set analysis of GWAS data. PLOS Computational Biology, 11, e1004219.

Deary, I. J., Whalley, L. J., Lemmon, H., Crawford, J. R., \& Starr, J. M. (2000). The stability of individual differences in mental ability from childhood to old age: Follow-up of the 1932 Scottish Mental Survey. Intelligence, 28, 49-55.

Demontis, D., Walters, R. K., Martin, J., Mattheisen, M., Als, T. D., Agerbo, E., ... Neale, B. M. (2019). Discovery of the first genome-wide significant risk loci for attention deficit/hyperactivity disorder. Nature Genetics, 51, 63-75.

Deriziotis, P., \& Fisher, S. E. (2017). Speech and language: Translating the genome. Trends in Genetics, 33, 642-656.

Duffy, D. L., Zhu, G., Li, X., Sanna, M., Iles, M. M., Jacobs, L. C., . . Martin, N. G. (2018). Novel pleiotropic risk loci for melanoma and nevus density implicate multiple biological pathways. Nature Communications, 9, 4774.

Dykiert, D., \& Deary, I. J. (2013). Retrospective validation of WTAR and NART scores as estimators of prior cognitive ability using the Lothian Birth Cohort 1936. Psychological Assessment, 25, 1361-1366. 
Fisher, S. E., \& Scharff, C. (2009). FOXP2 as a molecular window into speech and language. Trends in Genetics, 25, 166-177.

Fisher, S. E., Vargha-Khadem, F., Watkins, K. E., Monaco, A. P., \& Pembrey, M. E. (1998). Localisation of a gene implicated in a severe speech and language disorder. Nature Genetics, 18, 168-170.

Francks, C., Paracchini, S., Smith, S. D., Richardson, A. J., Scerri, T. S., Cardon, L. R., ... Monaco, A. P. (2004). A 77-kilobase region of chromosome 6p22.2 is associated with dyslexia in families from the United Kingdom and from the United States. American Journal of Human Genetics, 75, 1046-1058.

Galaburda, A. M., LoTurco, J., Ramus, F., Fitch, R. H., \& Rosen, G. D. (2006). From genes to behavior in developmental dyslexia. Nature Neuroscience, 9 , 1213-1217.

Garnier, H. E., Stein, J. A., \& Jacobs, J. K. (1997). The process of dropping out of high school: A 19-year perspective. American Educational Research Journal, 34, 395-419.

Gathercole, S. E. (2006). Nonword repetition and word learning: The nature of the relationship. Applied Psycholinguistics, 27, 513-543.

Gathercole, S. E., Willis, C. S., Baddeley, A. D., \& Emslie, H. (1994). The Children's Test of Nonword Repetition: A test of phonological working memory. Memory, 2, 103-127.

Guidi, L. G., Velayos-Baeza, A., Martinez-Garay, I., Monaco, A. P., Paracchini, S., Bishop, D. V. M., \& Molnar, Z. (2018). The neuronal migration hypothesis of dyslexia: A critical evaluation 30 years on. European Journal of Neuroscience, 48, 3212-3233.

Haplotype Reference Consortium, McCarthy, S., Das, S., Kretzschmar, W., Delaneau, O., Wood, A. R., ... Marchini, J. (2016). A reference panel of 64,976 haplotypes for genotype imputation. Nature Genetics, 48, 1279.

Harlaar, N., Spinath, F. M., Dale, P. S., \& Plomin, R. (2005). Genetic influences on early word recognition abilities and disabilities: A study of 7-year-old twins. Journal of Child Psychology and Psychiatry, 46, 373-384.

Holdnack, H. A. (2001). Wechsler Test of Adult Reading: WTAR. San Antonio, TX: The Psychological Corporation.

Huttunen, H. J., Kuja-Panula, J., Sorci, G., Agneletti, A. L., Donato, R., \& Rauvala, H. (2000). Coregulation of neurite outgrowth and cell survival by amphoterin and $\mathrm{S} 100$ proteins through receptor for advanced glycation end products (RAGE) activation. Journal of Biological Chemistry, 275, 40096-40105.

Lai, C. S., Fisher, S. E., Hurst, J. A., Vargha-Khadem, F., \& Monaco, A. P. (2001). A forkhead-domain gene is mutated in a severe speech and language disorder. Nature, 413, 519-523.

Leonard, L. B. (1991). Specific language impairment as a clinical category. Language, Speech, and Hearing Services in Schools, 22, 66-68.

Leonard, L. B. (2014). Children with specific language impairment. Cambridge: MIT Press.

Lind, P. A., Luciano, M., Wright, M. J., Montgomery, G. W., Martin, N. G., \& Bates, T. C. (2010). Dyslexia and DCDC2: normal variation in reading and spelling is associated with DCDC2 polymorphisms in an Australian population sample. European Journal of Human Genetics, 18, 668-673.

Luciano, M., Gow, A. J., Pattie, A., Bates, T. C., \& Deary, I. J. (2018). The influence of dyslexia candidate genes on reading skill in old age. Behavior Genetics, 48, 351-360.

MacDermot, K. D., Bonora, E., Sykes, N., Coupe, A. M., Lai, C. S., Vernes, S. C., ... Fisher, S. E. (2005). Identification of FOXP2 truncation as a novel cause of developmental speech and language deficits. American Journal of Human Genetics, 76, 1074-1080.

Matsson, H., Huss, M., Persson, H., Einarsdottir, E., Tiraboschi, E., NopolaHemmi, J., ... Kere, J. (2015). Polymorphisms in DCDC2 and S100B associate with developmental dyslexia. Journal of Human Genetics, 60, 399-401.

McArdle, J. J., Ferrer-Caja, E., Hamagami, F., \& Woodcock, R. W. (2002). Comparative longitudinal structural analyses of the growth and decline of multiple intellectual abilities over the life span. Developmental Psychology, $38,115-142$.

Medland, S. E., Nyholt, D. R., Painter, J. N., McEvoy, B. P., McRae, A. F., Zhu, G., . . Martin, N. G. (2009). Common variants in the trichohyalin gene are associated with straight hair in Europeans. American Journal of Human Genetics, 85, 750-755.
Meng, H., Smith, S. D., Hager, K., Held, M., Liu, J., Olson, R. K., ... Gruen, J. R. (2005). DCDC2 is associated with reading disability and modulates neuronal development in the brain. Proceedings of the National Academy of Sciences of the United States of America, 102, 17053-17058.

Morgan, A., Fisher, S. E., Scheffer, I., \& Hildebrand, M. (1993). FOXP2related speech and language disorders. In M. P. Adam, H. H. Ardinger, R. A. Pagon, S. E. Wallace, L. J. H. Bean, K. Stephens, \& A. Amemiya (Eds.), Gene reviews [Internet]. Seattle, WA: University of Washington.

Mueller, K. L., Murray, J. C., Michaelson, J. J., Christiansen, M. H., Reilly, S., \& Tomblin, J. B. (2016). Common genetic variants in FOXP2 are not associated with individual differences in language development. PLoS One, 11, e0152576-e0152576.

Nelson, H. E., \& Willison, J. (1991). National Adult Reading Test (NART) test manual. Windsor, UK: NFER-Nelson Publishing Company.

Newbury, D. F., Bishop, D. V., \& Monaco, A. P. (2005). Genetic influences on language impairment and phonological short-term memory. Trends in Cognitive Sciences, 9, 528-534.

Newbury, D. F., Paracchini, S., Scerri, T. S., Winchester, L., Addis, L., Richardson, A. J., .. Monaco, A. P. (2011). Investigation of dyslexia and SLI risk variants in reading- and language-impaired subjects. Behavior Genetics, 41, 90-104.

Newbury, D. F., Winchester, L., Addis, L., Paracchini, S., Buckingham, L. L., Clark, A., ... Monaco, A. P. (2009). CMIP and ATP2C2 modulate phonological short-term memory in language impairment. American Journal of Human Genetics, 85, 264-272.

Nopola-Hemmi, J., Myllyluoma, B., Haltia, T., Taipale, M., Ollikainen, V., Ahonen, T., ... Widen, E. (2001). A dominant gene for developmental dyslexia on chromosome 3. Journal of Medical Genetics, 38, 658-664.

Nyholt, D. R. (2004). A simple correction for multiple testing for single-nucleotide polymorphisms in linkage disequilibrium with each other. American Journal of Human Genetics, 74, 765-769.

Paracchini, S., Scerri, T., \& Monaco, A. P. (2007). The genetic lexicon of dyslexia. Annual Review of Genomics and Human Genetics, 8, 57-79.

Poelmans, G., Buitelaar, J. K., Pauls, D. L., \& Franke, B. (2011). A theoretical molecular network for dyslexia: integrating available genetic findings. Molecular Psychiatry, 16, 365-382.

Poelmans, G., Engelen, J. J., Van Lent-Albrechts, J., Smeets, H. J., Schoenmakers, E., Franke, B., ... Schrander-Stumpel, C. (2009). Identification of novel dyslexia candidate genes through the analysis of a chromosomal deletion. American Journal of Medical Genetics Part B: Neuropsychiatric Genetics, 150B, 140-147.

Purcell, S., Cherny, S. S., \& Sham, P. C. (2003). Genetic power calculator: Design of linkage and association genetic mapping studies of complex traits. Bioinformatics, 19, 149-150.

Reuter, M. S., Riess, A., Moog, U., Briggs, T. A., Chandler, K. E., Rauch, A., ... Zweier, C. (2017). FOXP2 variants in 14 individuals with developmental speech and language disorders broaden the mutational and clinical spectrum. Journal of Medical Genetics, 54, 64-72.

Ritchie, S. J., \& Bates, T. C. (2013). Enduring links from childhood mathematics and reading achievement to adult socioeconomic status. Psychological Science, 24, 1301-1308.

Rodgers, B. (1983). The identification and prevalence of specific reading retardation. British Journal of Educational Psychology, 53, 369-373.

Scerri, T. S., Morris, A. P., Buckingham, L. L., Newbury, D. F., Miller, L. L., Monaco, A. P., ... Paracchini, S. (2011). DCDC2, KIAA0319 and CMIP are associated with reading-related traits. Biological Psychiatry, 70, 237-245.

SLI Consortium. (2002). A genomewide scan identifies two novel loci involved in specific language impairment. American Journal of Human Genetics, 70, 384-398.

Smith, M. C. (1993). Change in reading ability and attitudes from childhood to adulthood: A life span perspective. In S. R. Yussen (Ed.), Reading across the life span (pp. 273-291). New York: Springer.

Smith, M. C. (1996). Differences in adults' reading practices and literacy proficiencies. Reading Research Quarterly, 31, 196-219.

Snowling, M. J., Adams, J. W., Bishop, D. V., \& Stothard, S. E. (2001). Educational attainments of school leavers with a preschool history of 
speech-language impairments. International Journal of Language \& Communication Disorders, 36, 173-183.

Stark, R. E., \& Tallal, P. (1981). Selection of children with specific language deficits. Journal of Speech and Hearing Disorders, 46, 114-122.

Uddén, J., Hulten, A., Bendtz, K., Mineroff, Z., Kucera, K. S., Vino, A., . . Fisher, S. E. (2019). Toward robust functional neuroimaging genetics of cognition. Journal of Neuroscience, 39, 8778-8787.

Vernes, S. C., Newbury, D. F., Abrahams, B. S., Winchester, L., Nicod, J., Groszer, M., ... Fisher, S. E. (2008). A functional genetic link between distinct developmental language disorders. New England Journal of Medicine, 359, 2337-2345.

Wiszniewski, W., Hunter, J. V., Hanchard, N. A., Willer, J. R., Shaw, C., Tian, Q., ... Lalani, S. R. (2013). TM4SF20 ancestral deletion and susceptibility to a pediatric disorder of early language delay and cerebral white matter hyperintensities. American Journal of Human Genetics, 93, 197-210.

Yang, J., Lee, S. H., Goddard, M. E., \& Visscher, P. M. (2011). GCTA: A tool for genome-wide complex trait analysis. American Journal of Human Genetics, 88, 76-82. 